\title{
PSD-95 Interacts with NBCn1 and Enhances Channel-like Activity without Affecting $\mathrm{Na} / \mathrm{HCO}_{3}$ Cotransport
}

\author{
Soojung Lee ${ }^{a}$ Han Soo Yang a,d Eunjin Kim ${ }^{a, d}$ Eun Ji Ju ${ }^{a}$ Min Hyung Kwon ${ }^{a}$ \\ R. Kyle Dudley ${ }^{\mathrm{a}} \quad$ Yoland Smith $^{\mathrm{b}} \quad$ C. Chris Yun ${ }^{\mathrm{c}}$ Inyeong Choi

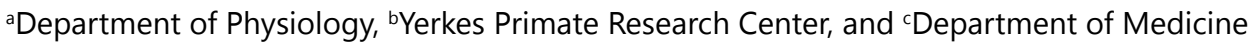 \\ Division of Digestive Diseases, Emory University School of Medicine, Atlanta, GA, \\ dequal contribution
}

\section{Key Words}

Bicarbonate transport • Acid-base $\bullet \mathrm{pH} \cdot$ Electrophysiology $\bullet$ Neuron $\bullet$ Xenopus

\begin{abstract}
Background/Aims: The sodium/bicarbonate transporter NBCn1 plays an essential role in intracellular $\mathrm{pH}$ regulation and transepithelial $\mathrm{HCO}_{3}^{-}$movement in the body. $\mathrm{NBCn} 1$ also has sodium channel-like activity uncoupled to $\mathrm{Na} / \mathrm{HCO}_{3}$ cotransport. We previously reported that NBCn1 interacts with the postsynaptic density protein PSD-95 in the brain. Here, we elucidated the structural determinant and functional consequence of NBCn1/PSD-95 interaction. Methods: Results: In rat hippocampal CA3 neurons, NBCn1 was localized to the postsynaptic membranes of both dendritic shafts and spines and occasionally to the presynaptic membranes. A GST/NBCn1 fusion protein containing the C-terminal 131 amino acids of NBCn1 pulled down PSD-95 from rat brain lysates, whereas GST/NBCn1- $\triangle E T S L$ (deletion of the last four amino acids) and GST/NBCn2 (NCBE) lacking the same ETSL did not. NBCn1 and PSD-95 were coimmunoprecipitated in HEK 293 cells, and their interaction did not affect the efficacy of PSD-95 to bind to the NMDA receptor NR2A. PSD-95 has negligible effects on intracellular $\mathrm{pH}$ changes mediated by NBCn1 in HEK 293 cells and Xenopus oocytes. However, PSD-95 increased an ionic conductance produced by NBCn1 channel-like activity. This increase was abolished by NBCn1- $\triangle E T S L$ or by the peptide containing the last 15 amino acids of NBCn1. Conclusion: Our data suggest that PSD-95 interacts with NBCn1 and increases its channel-like activity while negligibly affecting $\mathrm{Na} / \mathrm{HCO}_{3}$ cotransport. The possibility that the channel-like activity occurs via an intermolecular cavity of multimeric NBCn1 proteins is discussed.
\end{abstract}

Copyright (c) 2012 S. Karger AG, Basel

\section{Introduction}

$\mathrm{NBCn} 1$ (SLC4A7) is an ion transporter that normally moves $\mathrm{Na}^{+}$and $\mathrm{HCO}_{3}{ }^{-}$into cells $[1,2]$. NBCn1 contributes to transepithelial movement of ions and acid/base equivalents in epithelial cells and intracellular $\mathrm{pH}\left(\mathrm{pH}_{\mathrm{i}}\right)$ regulation in non-epithelial cells [3, 4]. Slc4a7 knockout mice 
develop gradual degeneration of sensory neurons in the ears and eyes [5]. Knockout mice are slightly hypertensive but are resistant to angiotensin II-induced hypertension due to abnormal $\mathrm{pH}$ regulation in vascular smooth muscles and endothelial cells [6]. In addition to $\mathrm{Na} / \mathrm{HCO}_{3}$ cotransport activity, $\mathrm{NBCn} 1$ has a channel-like activity that produces a steady-state current primarily mediated by $\mathrm{Na}^{+}$in an $\mathrm{Na} / \mathrm{HCO}_{3}$ cotransport-independent manner [2, 7]. The physiological role of this channel-like activity is unclear although it has been proposed to depolarize the membrane by raising steady-state intracellular $\mathrm{Na}^{+}$levels $[2,7]$.

NBCn1 can interact with many different proteins in tissue-specific manners [8]. The interaction mainly involves the C-terminal last four amino acids ETSL, to which many PDZ proteins bind (PDZ stands for Post synaptic density protein PSD95, Drosophila disc large tumor suppressor Dlg1, and Zonula occludens-1 protein zo-1). In the kidney, NBCn1 binds to the $56 \mathrm{kDa}$ protein subunit of H-ATPase and tethers with H-ATPases on the same side of the membrane [9]. In the pancreatic ducts and salivary glands, NBCn1 binds to the scaffold protein NHERF-1/EBP50 and modulates luminal $\mathrm{HCO}_{3}^{-}$release mediated by $\mathrm{Cl}^{-}$ channels [10]. In the ears, NBCn1 binds to harmonin in a macromolecular network, which is required for the development and maintenance of hair cells [11]. NBCn1 can also bind to carbonic anhydrase II although this interaction does not involve the C-terminal ETSL of the transporter [12]. We previously reported that NBCn1 interacts with the postsynaptic density protein PSD-95 in rodent brains [13]. In primary cultures of rat hippocampal neurons [7] and hippocampal slices [13], the two proteins are partially colocalized in dendritic processes. The colocalization is partial as PSD-95 interacts with a variety of different proteins [14].

The roles of PSD-95 are diverse: it can alter activities of its binding partners, tether the partners to membrane-associated cytoskeletal proteins, recruit signaling proteins, and cluster functionally coupled proteins into microdomains near cell membranes $[14,15]$. Whether PSD-95 affects NBCn1 function is presently unclear. In this study, we investigated the structural determinant and functional implication of the interaction between NBCn1 and PSD-95. We examined NBCn1 localization at synapses and performed molecular and biochemical experiments to characterize its interaction with PSD-95. We also performed electrophysiological experiments to evaluate the effects of PSD-95 on NBCn1 cotransport and channel-like activity. The results suggest that PSD-95 is an important protein capable of modulating NBCn1 function.

\section{Materials and Methods}

All experiments in this study were conducted under the National Institute of Health guidelines for research on animals, and experimental protocols were approved by the Institutional Animal Care and Use Committee at Emory University.

\section{Electron microscopic immunoperoxidase}

Electron microscopic immunohistochemistry was performed using the previous protocol [16] with slight modification. Briefly, adult rats (Sprague Dawley from Harlan; Indianapolis, IN, USA) were fixed in 4\% paraformaldehyde and $0.1 \%$ glutaraldehyde, and brains were cut into 10 -mm-thick blocks. Hippocampal sections $(60 \mu \mathrm{m})$ were treated in $1 \%$ sodium borohydride and then placed in a cryoprotectant solution ( $25 \%$ sucrose and $10 \%$ glycerol) for $20 \mathrm{~min}$ and frozen at $-80^{\circ} \mathrm{C}$ for $20 \mathrm{~min}$. The sections were thawed and treated with a serial dilution of cryoprotectant (100-30\%). After washes in PBS, the sections were treated with $10 \%$ normal goat serum and $1 \%$ bovine serum albumin, and incubated with 1:200 diluted NBCn1 antibody [17] at $4^{\circ} \mathrm{C}$. The sections were incubated with biotinylated goat anti-rabbit IgG (1:200; Vector Laboratories; Burlingame, CA, USA) for $1.5 \mathrm{~h}$ and then the DAB staining was done. Post-fixation was done in $1 \%$ osmium tetroxide and dehydration in a serial dilution of ethanol and propylene oxide. The sections were embedded in epoxy resin Durcupan ACM (Sigma-Aldrich; St. Louis, MO, USA), incubated at $60^{\circ} \mathrm{C}$ for 2 days, and glued to the resin blocks. Ultrathin sections were collected onto Pioloform-coated single-slot copper grids and stained with lead citrate. The sections were visualized with a Zeiss EM 10C electron microscope. Images were analyzed DigitalMicrograph software (Gatan; Pleasanton, CA, USA).

Double-label immunofluorescence

Double label of NBCn1 and PSD-95 immunofluorescence was performed as described previously [18]. Mouse brains were fixed with ice-cold $4 \%$ paraformaldehyde and brains sections $(30 \mu \mathrm{m})$ were washed 
with PBS containing $0.1 \%$ Tween 20 and then blocked with $10 \%$ normal goat serum for 1 h. The sections were incubated with the rabbit NBCn1 antibody (1:100) and the mouse PSD-95 antibody (1:100) at $4^{\circ} \mathrm{C}$ overnight. The secondary antibodies were Alexa 488 anti-rabbit IgG (1:500; Invitrogen; Carlsbad, CA) and Alexa 594 anti-mouse IgG (1:500; Invitrogen) for $1 \mathrm{~h}$ incubation. The sections were mounted onto gelatincoated slides with Vectashield (Vector Laboratories; Burlingame, CA, USA), covered with coverslips, and visualized using an Olympus Fluoview FV1000 confocal microscope with UPLFLN 40× and 100× objectives (numerical aperture 1.3). Images of CA3 neurons were acquired using Olympus software.

\section{Pull-down assay}

The following GST fusion proteins were prepared: GST/NBCn1 containing the C-terminal 131 amino acids of rat NBCn1-E; GST/NBCn1- $\triangle$ ETSL that lacks the last 4 amino acids ETSL of NBCn1-E; GST/NBCn2 containing the C-terminal 113 amino acids of rat NBCn2-C (i.e., rb2NCBE). Fusion proteins were constructed by subcloning the corresponding nucleotides into pGEX-4T (GE Healthcare; Chicago, IL, USA). Brains of adult rats were homogenized in the lysis buffer $(300 \mathrm{mM}$ mannitol, $0.1 \mathrm{mg} / \mathrm{ml}$ phenylmethanesulphonyl fluoride, $5 \mathrm{mM}$ HEPES, $1 \times$ protease inhibitor cocktail, $\mathrm{pH} 7.2$ ) and centrifuged at $3,000 \times g$ for $10 \mathrm{~min}$ to remove cell debris. The lysates were then incubated with GST only or GST fusion proteins bound to glutathione-Sepharose beads for $4 \mathrm{~h}$. The beads were washed 4 times with $0.5 \%$ Nonidet P-40 in PBS, and proteins bound to the beads were dissociated by adding the SDS-PAGE sample loading buffer. Immunoblot was performed with the mouse PSD-95 antibody (1:500; Affinity Bioreagents; Golden, CO, USA). In parallel experiments, GST only or GST fusion proteins bound to glutathione-Sepharose beads were loaded on the gel and stained with Coomassie blue to visualize the molecular weight of the fusion proteins.

\section{Coimmunoprecipitation}

HEK 293 cells were transfected with pcDNA3.1/NBCn1, GW1/myc-PSD-95, pcDNA3.1/NR1A, and pcDNA3.1/NR2A using Lipofectamine 2000 (Life Technologies; Grand Island, NY) according to the manufacturer's protocol. The amounts of plasmids were $4 \mu \mathrm{g}$ NR1A/NR2A, $4 \mu \mathrm{g}$ PSD-95, and $0.5-4 \mu \mathrm{g}$ NBCn 1 to transfect $2-6 \times 10^{6}$ cells. NR1A was omitted in some experiments as it did not significantly affect NR2A/PSD-95 interaction. pcDNA3.1 vector served as a control. At $48 \mathrm{~h}$ after transfection, cells were lysed in $20 \mathrm{mM}$ HEPES, $150 \mathrm{mM}$ NaCl, $2 \mathrm{mM}$ EDTA, $10 \%$ glycerol, $0.5 \%$ Nonidet P-40, and $1 \times$ protease inhibitor cocktail, and centrifuged at $13,200 \times g$ for 15 min. Supernatants were pre-treated with Protein A/G agarose beads at $4^{\circ} \mathrm{C}$ for $20 \mathrm{~min}$ to block non-specific bead binding. Beads were removed, and the lysates were incubated with the PSD-95 antibody at $4^{\circ} \mathrm{C}$ overnight in $100 \mathrm{mM} \mathrm{NaCl}, 0.5 \%$ Triton $\mathrm{X}-100,0.2 \%$ sodium deoxycholate, and $20 \mathrm{mM}$ HEPES, pH 7.4. Fresh beads were added to the lysates and agitated for $1 \mathrm{~h}$. Beads were collected and washed, and proteins were dissociated from the beads by adding the SDS-PAGE sample loading buffer. Immunoblot was performed with the NBCn1 antibody and the NR2A antibody (Millipore; Billerica, MA, USA).

\section{Immunoblotting}

HEK 293 cells and oocytes were homogenized with a 26 gauge needle in ice-cold lysis buffer and centrifuged at $810 \times g$ for $10 \mathrm{~min}$ to remove cell debris. Crude plasma membranes were prepared by centrifugation at $100,000 \times g$ for $30 \mathrm{~min}$ at $4^{\circ} \mathrm{C}$. Protein concentration in the membrane preparation was quantitated using the Bradford reagents (Sigma-Aldrich). The equal amounts of protein samples (10-30 $\mu \mathrm{g}$ ) were loaded on a 7.5\% SDS-PAGE and blotted to a nitrocellulose membrane. The blot was treated with blocking buffer containing 0.05\% Tween 20 and 5\% non-fat dry milk in PBS for $1 \mathrm{~h}$ and then with primary antibodies for $1 \mathrm{~h}$. After washes with PBS containing $0.05 \%$ Tween 20 for 5 min 4 times, the blot was treated with a horseradish peroxidase-conjugated anti-rabbit or anti-mouse secondary antibody for $1 \mathrm{~h}$ (1:2500; Millipore). After washes, the blot was treated with the chemiluminescence detection solution from the ECL kit (GE Healthcare). The blot was striped and reprobed for $\beta$-actin. For densitometric comparison, pixel intensities of the immunoreactive bands were measured by positioning boxes around the bands using ImageJ image analysis software (NIH; Bethesda, MD, USA). NBCn1 or NR2A were normalized to $\beta$-actin after background subtraction.

Measurements of $\mathrm{pH}_{i}$ in HEK 293 cells

Cells growing on a coverslip $\left(2.2 \times 10^{5}\right.$ cells in a $60-\mathrm{mm}$ dish $)$ were transfected as described above and incubated for $36 \mathrm{~h}$. Cells were loaded with $6.5 \mu \mathrm{M}$ of bis-carboxyethyl carboxyfluorescein acetoxymethyl ester (BCECF-AM) for $10 \mathrm{~min}$, and the coverslip was mounted to a chamber RC-30 (Harvard Apparatus; Holliston, MA, USA) affixed on the stage of a Nikon TE200 inverted microscope. Cells were perfused with HEPES-buffered solution (mM: $140 \mathrm{NaCl}, 1 \mathrm{KCl}, 1 \mathrm{MgSO}_{4}, 2 \mathrm{CaCl}_{2}, 2.5 \mathrm{NaH}_{2} \mathrm{PO}_{4}, 5.5$ glucose, and $10 \mathrm{HEPES}$, $\mathrm{pH}$ 7.5). The $\mathrm{HCO}_{3}^{-} / \mathrm{CO}_{2}$-buffered solution was made by replacing $33 \mathrm{mM}$ NaCl in HEPES-buffered solution with $33 \mathrm{mM} \mathrm{NaHCO}, 5 \% \mathrm{CO}_{2}(\mathrm{pH} 7.5)$. The two solutions contained $10 \mu \mathrm{M}$ ethyl isopropyl amiloride to inhibit endogenous $\mathrm{Na} / \mathrm{H}$ exchanger. At the end of the experiments, cells were exposed to a high $\mathrm{K}^{+} /$nigericin solution [19] of pH 6.8. The dye was alternately excited with $500 \mathrm{~nm}$ and $440 \mathrm{~nm}$ light using a Lambda 10-2 filter wheel controller (Sutter Instruments; Novato, CA, USA) and the $530 \mathrm{~nm}$ emission lights from both excitations were captured. The ratio of the emission intensities at $500 \mathrm{~nm}$ to $440 \mathrm{~nm}$ was calculated and normalized to the ratio in the $\mathrm{K}^{+} /$nigericin solution. Background subtraction was made from the area without 
cells. The ratio was converted to $\mathrm{pH}$ using a calibration curve constructed from the ratios at different $\mathrm{pH}$, ranging from 6.0 to 8.0. Data were acquired using Metafluor software (Universal Imaging, Downingtown, PA, USA). The rate of $\mathrm{pH}$ changes (i.e., $\mathrm{dpH}_{\mathrm{i}} / \mathrm{dt}$ ) was calculated from the slope of a linear regression line during the first 30 seconds of recovery. The degree of $\mathrm{CO}_{2}$-induced acidification was similar among cells expressing $\mathrm{NBCn} 1$ only or NBCn1/PSD-95. All experiments were performed at $37^{\circ} \mathrm{C}$.

\section{Protein expression in Xenopus oocytes}

Oocytes were prepared as described previously [7]. Briefly, frogs were purchased from Xenopus Express (Brooksville, FL, USA). A frog was anesthetized with fresh 0.1\% 3-aminobenzoic acid ethyl ester for $20 \mathrm{~min}$ and surgery was done below the termination of sternum to collect ovary. After suture, the frog was returned to a recovery tank containing $0.1 \mathrm{M} \mathrm{NaCl}$. Oocytes were agitated with $\mathrm{Ca}^{2+}$-free ND96 solution (mM; $96 \mathrm{NaCl}, 2 \mathrm{KCl}, 1 \mathrm{MgCl}_{2}$, and 10 HEPES, pH 7.5) five times for $20 \mathrm{~min}$ each, and then with type IA collagenase (2 mg/ml; Sigma-Aldrich) twice for $20 \mathrm{~min}$ each. Stage V-VI oocytes were sorted under the dissection microscope and stored at $18^{\circ} \mathrm{C}$ overnight. For injection, cRNAs of NBCn1, PSD-95, and NR1A/ NR2A were made using the mMessage/mMachine kit (Life Technologies). The amount of injected cRNA (in $46 \mathrm{nl}$ ) was $11 \mathrm{ng}$ for NBCn1, $7.5 \mathrm{ng}$ for PSD-95, $5 \mathrm{ng}$ for NR1A and $12.5 \mathrm{ng}$ for NR2A. Thus, the ratio of NR1A to NR2A was 1 to 2.5. For pH measurements, $35 \mathrm{ng}$ for each NBCn1 and PSD-95 were used. Control oocytes were injected with sterile water or uninjected. Oocytes were maintained at $18^{\circ} \mathrm{C}$ for $3-4$ days before use.

\section{Measurements of $\mathrm{pH}_{i}$ in oocytes}

Oocyte $\mathrm{pH}_{\mathrm{i}}$ was measured using the protocol [20] with slight modification. A glass capillary was filled with the proton ionophore 1 cocktail B (Sigma-Aldrich) and back-filled with the phosphate buffer (pH 7.0). This $\mathrm{pH}$ electrode was connected to a high-impedance electrometer FD-223 (World Precision Instruments, Sarasota, FL, USA) routed to a custom-made subtraction amplifier. A second glass capillary filled with $3 \mathrm{M}$ $\mathrm{KCl}$ was connected to a voltage clamp amplifier OC-725C (Harvard Apparatus). Signals were sampled by a Digidata 1322A (Molecular Devices; Sunnyvale, CA) and data were acquired using pClamp 8 (Molecular Devices). The signal in voltage electrode was subtracted from that in $\mathrm{pH}$ electrode to calculate the voltage for $\mathrm{pH}$. The slope of voltage to $\mathrm{pH}$ was determined using $\mathrm{pH} 6.0$ and 8.0 standards (typically $53 \pm 3 \mathrm{mV} / \mathrm{pH}$ ). Recording was done in $\mathrm{HCO}_{3}{ }^{-} / \mathrm{CO}_{2}$-free ND96 solution (mM; $96 \mathrm{NaCl}, 2 \mathrm{KCl}, 1 \mathrm{MgCl}_{2}, 1.8 \mathrm{CaCl}_{2}, 5 \mathrm{HEPES}$, pH 7.4; $195-200 \mathrm{mOsm} / \mathrm{kg}$ ) and in a solution buffered with $25 \mathrm{mM} \mathrm{HCO}_{3}^{-}, 5 \% \mathrm{CO}_{2}(\mathrm{pH} 7.4)$. The dpH $/ \mathrm{dt}_{\mathrm{i}}$ was calculated from a linear regression line during the first 2 min of recovery. Experiments were performed at room temperature.

\section{Two-electrode voltage clamp}

Two-electrode voltage clamp was performed to record the steady-state current produced by NBCn1. A glass capillary was filled with $3 \mathrm{M} \mathrm{KCl}$ and connected to a voltage headstage, and another capillary was connected to a current cable (tip resistance of 1-2 $\mathrm{M} \Omega$ for each). The voltage and current cables were then connected to OC-725C. Oocytes were impaled with the two electrodes in ND96 solution and clamped at $-60 \mathrm{mV}$. After the holding currents became stable, voltage commands from $-120 \mathrm{mV}$ to $+60 \mathrm{mV}$ with 20 $\mathrm{mV}$ increments were applied with the duration of $100 \mathrm{msec}$. Current-voltage $(I-V)$ relationships were then obtained, from which NBCn1-associated ionic conductance was calculated by determining a slope near the zero-current voltage [21]. For peptide competition experiments, the peptide (EDEPSKKYMDAETSL) corresponding to the last 15 amino acids of rat $\mathrm{NBCn} 1$ was injected at the concentration of $0.05 \mu \mathrm{g}$ per oocyte $48 \mathrm{~h}$ after oocytes were injected with NBCn1 or NBCn1/PSD-95. Voltage clamp experiments were then done $36 \mathrm{~h}$ later to calculate NBCn1-associated ionic conductance.

\section{Statistical analysis}

Data were reported as means \pm standard error. Levels of significance were assessed using unpaired, 2-tailed Student $t$-test to analyze $i$ ) $\mathrm{pH}_{\mathrm{i}}$ recovery rate and slope conductance of NBCn1 affected by PSD95 and ii) slope conductance of NBCn1 or NBCn1/PSD-95 affected by the peptide. The one-way ANOVA with Bonferroni post test was used to analyze $i) \mathrm{pH}_{\mathrm{i}}$ recovery rate and conductance among NBCn1, NBCn1/ PSD-95, and either PSD-95 or control and ii) conductances among 4 groups of oocytes with/without $\mathrm{NBCn} 1(\Delta \mathrm{ETSL})$ or the peptide. The $p$ value of less than 0.05 was considered significant.

\section{Results}

NBCn1 is predominantly localized in dendritic shafts and spines

We performed electron microscopic immunoperoxidase staining of rat hippocampal CA3 neurons to determine synaptic expression of $\mathrm{NBCn} 1 . \mathrm{NBCn} 1$ is localized to both dendrites and cell bodies at the light microscopic level $[13,22]$. PSD-95 is predominantly localized to dendritic spines at the light and electron microscopic levels [23]. Thus, our experiments were done with the apical proximal dendrites where glutamatergic synapses are heavily 
Fig. 1. Localization of $\mathrm{NBCn} 1$ at synapses in hippocampal CA3 neurons. A) Electron micrographs of $\mathrm{NBCn} 1$ immunope-roxidase in dendrites. NBCn1positive dendrites contacted by unlabeled nerve terminals are shown. Dendritic spines positive to NBCn 1 are also indicated.
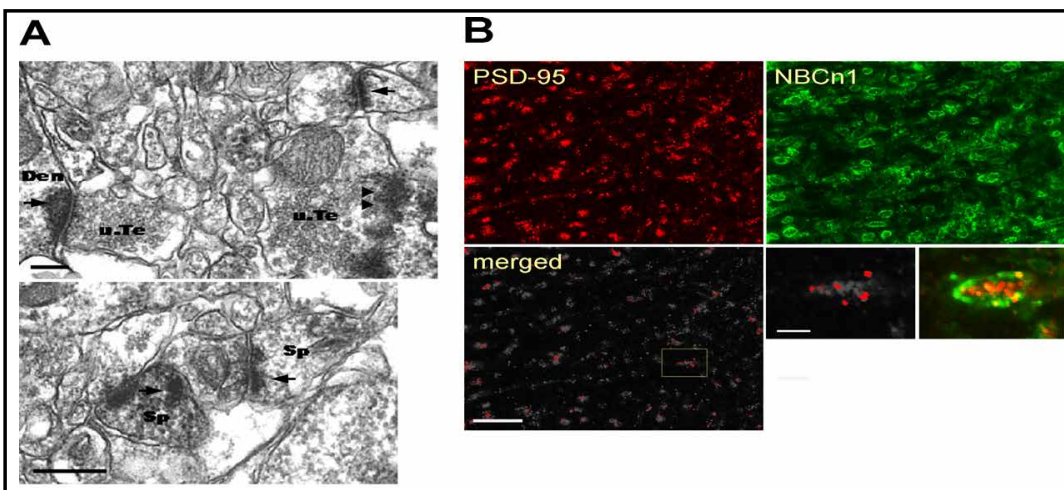

NBCn1 stainings are mostly in postsynaptic membranes (arrows) but often found in presynaptic stainings (arrow heads). Den, dendrite; Sp, spine; u.Te, unmyelinated terminal. Bar: $0.25 \mu \mathrm{m}$. B) Double-label immunofluorescence of NBCn1 and PSD-95 in CA3 pyramidal neurons. Alexa 488-labeled NBCn1 (green) and Alexa 594-labeled PSD-95 (red) were used. Images were taken in $100 \times$ magnification (bar: $10 \mu \mathrm{m}$ ). The areas, where the two immunofluorescence signals were merged (white areas), were identified using Image J software with the colocalization finder plug-in.

innervated. Fig. 1A shows electron micrographs of the stratum radiatum in cross section. NBCn1 immunoperoxidase staining was mostly confined to postsynaptic membranes. Both dendritic spines and shafts were positive for NBCn1. In addition, presynaptic membranes were occasionally stained. Fig. 1B shows confocal images of proximal dendrites doublelabeled with antibodies to NBCn1 (green; probed with Alexa 488 fluorescent dye) and PSD95 (red; probed with Alexa 594 fluorescent dye). NBCn1 was prominently dispersed along dendritic processes, whereas PSD-95 was mostly in puncta. The two fluorescence labelings frequently overlapped in large dendrites.

\section{NBCn1 interacts with PSD-95 via the C-terminal PDZ motif}

We previously demonstrated the interaction of NBCn1/PSD-95 in rat brain lysates by coimmunoprecipitation and GST pull-down assay [13]. To further assess the specificity of the interaction between NBCn1 and PSD-95, we performed pull-down assays in which rat brain lysates were incubated with GST/NBCn1 containing the C-terminal 131 amino acids of rat NBCn1, GST/NBCn2 containing the C-terminal 113 amino acids of rat NBCn2-C (i.e., rb2NCBE) and GST/NBCn1- $\triangle$ ETSL (the deletion of the last 4 amino acids ETSL in NBCn1). Probed with the PSD-95 antibody, the immunoblotting of pull-down samples detected a protein band ( $95 \mathrm{kDa}$ ) in GST/NBCn1 (Fig. $2 A$ ). The antibody recognized an additional weak band of $\sim 75 \mathrm{kDa}$ protein that was also present in the lysates. PSD-95 was not detected in GST alone and GST/NBCn2. GST/NBCn1- $\triangle$ ETSL was also negative, consistent with the idea that the NBCn1/PSD-95 interaction is mediated by the PDZ motif in the NBCn1 C-terminus. The interaction of NBCn1/PSD-95 was confirmed by coimmunoprecipitation using HEK 293 cells (Fig. 2B). Lysates from cells transfected with the two proteins were immunoprecipitated with the PSD- 95 antibody and then immunoblotted with the NBCn 1 antibody. The immunoblotting recognized NBCn1 in the precipitates from cells expressing NBCn1/PSD-95. The control cells expressing NBCn1 alone showed no NBCn1 in the precipitates.

Among proteins capable of binding to PSD-95, NMDA receptors are the major protein that constitutes the macromolecular complex with PSD-95 in the postsynaptic density [24, 25]. To test whether NBCn1/PSD-95 interaction affects the efficacy of PSD-95 to interact with NMDA receptors, we expressed NBCn1, PSD-95, and the NMDA receptor subunits NR1A and NR2A (hereafter NR1A + NR2A are referred to as NMDAR) in HEK 293 cells and performed coimmunoprecipitation (Fig. 2C and D). Cell lysates were immunoprecipitated with the PSD-95 antibody and then immunoblotted either with the NBCn1 antibody or the $\mathrm{NR} 2 \mathrm{~A}$ antibody. We found both $\mathrm{NBCn} 1$ and NR2A in the precipitates from cells expressing NBCn1/NMDAR/PSD-95 (Fig. 2C; lane 2). This detection was not due to incomplete wash 
Fig. 2. Interaction between $\mathrm{NBCn} 1$ and PSD-95. A) Pull-down assay. Rat brain lysates were incubated with either the GST/NBCn1 fusion protein containing the C-terminal 131 amino acids of NBCn1, GST/NBCn2 containing the C-terminal 113 amino acids of NBCn2 (NCBE), or GST/NBCn1-ETSL that lacks the last 4 amino acids of NBCn1. GST only served as a control. Pull-down samples were immunoblotted with the PSD-95 antibody. A weak band of $\sim 50 \mathrm{kDa}$ is nonspecific. Coomassie blue staining of the protein gel showed GST fusion proteins with the expected molecular weight. B) Coimmunoprecipitation. Lysates of HEK 293 cells expressing NBCn1/PSD-95 or NBCn1 alone were immunoprecipitated with the PSD95 antibody and then immunoblotted with the NBCn1 antibody. C)

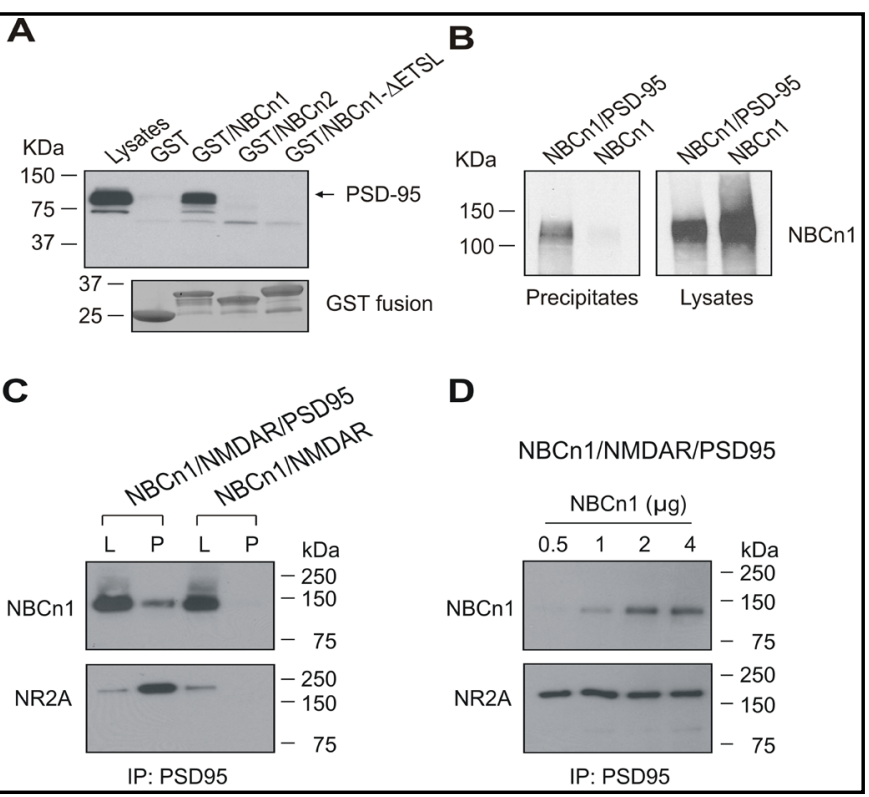
Coimmunoprecipitation of NBCn1/PSD-95 and PSD-95/NR2A. Lysates of cells expressing NBCn1, NR1A/ NR2A (i.e., NMDAR), and either PSD-95 or none were immunoprecipitated with the PSD-95 antibody and then immunoblotted with antibodies to $\mathrm{NBCn} 1$ and NR2A. The amount of the total protein in the lysates corresponds to one fifteenth of that in the precipitates. L, lysates; P, immunoprecipitates. D) Competition analysis of NBCn1/PSD-95 and PSD-95/NR2A. Cells were transfected with PSD-95, NMDAR and different amounts of $\mathrm{NBCn} 1(0.5-4 \mu \mathrm{g})$.

of Protein A/G beads after the lysate incubation because the immunoreactive bands were absent from cells expressing NBCn1 and NMDAR, but not PSD-95. Coimmunoprecipitation was then repeated with cells expressing PSD-95, NMDAR, and different amounts of NBCn1 (Fig. 2D). The NBCn1 signal intensity was progressively stronger at the higher amounts of NBCn1 for transfection, whereas the NR2A intensity remained unaffected under the same condition. The similar intensity in all lanes demonstrates that NBCn1/PSD-95 interaction occurs without affecting the PSD-95/NMDAR interaction.

\section{PSD-95 has negligible effects on NBCn1-mediated $p H_{i}$ change}

To examine the functional effect of PSD-95 on NBCn1, we measured $\mathrm{pH}_{\mathrm{i}}$ of HEK 293 cells expressing $\mathrm{NBCn} 1$ and PSD-95 or vector using the $\mathrm{pH}$-sensitive fluorescence dye BCECF-AM. NBCn1 moves $\mathrm{HCO}_{3}{ }^{-}$into the cells and raises $\mathrm{pH}_{\mathrm{i}}$, and thus experiments were focused on monitoring $\mathrm{pH}_{\mathrm{i}}$ recovery from an acid load in the presence of $\mathrm{HCO}_{3}^{-} / \mathrm{CO}_{2}$. Solutions contained $100 \mu \mathrm{M}$ EIPA to block endogenous $\mathrm{Na} / \mathrm{H}$ exchanger activity. Fig. $3 \mathrm{~A}$ shows representative $\mathrm{pH}_{\mathrm{i}}$ traces during the application of $33 \mathrm{mM} \mathrm{HCO}_{3}^{-}, 5 \% \mathrm{CO}_{2}(\mathrm{pH} 7.5)$. Applying $\mathrm{HCO}_{3}^{-} / \mathrm{CO}_{2}$ caused an abrupt fall in $\mathrm{pH}_{\mathrm{i}}$ as $\mathrm{CO}_{2}$ entered into cells and produced $\mathrm{H}^{+}$after hydration. The $\mathrm{pH}_{\mathrm{i}}$ was then recovered from the $\mathrm{CO}_{2}$-induced acidification as $\mathrm{NBCn} 1$ moved $\mathrm{HCO}_{3}^{-}$into the cells and buffered $\mathrm{H}^{+}$. The $\mathrm{pH}_{\mathrm{i}}$ change during this recovery was similar in the two groups of cells expressing NBCn1/PSD-95 and $\mathrm{NBCn} 1$ alone. The resting $\mathrm{pH}_{\mathrm{i}}$ and $\mathrm{CO}_{2}$-induced acidification were also similar in these cells, reflecting that the buffering powers are not different. Fig. 3B summarizes the mean rate of $\mathrm{pH}_{\mathrm{i}}$ change $\left(\mathrm{dpH}_{\mathrm{i}} / \mathrm{dt}\right)$ during the recovery from acidification $(\mathrm{n}$ $=6-8$ cells from one coverslip for each group; triplicate experiments). No significant change in $\mathrm{dpH}_{\mathrm{i}} / \mathrm{dt}$ was found regardless of PSD-95 $\left(110 \pm 13 \times 10^{-5} \mathrm{pH}\right.$ units/sec for NBCn1 and 114 $12 \times 10-5 \mathrm{pH}$ units/sec for NBCn1/PSD-95; $\mathrm{p}>0.05$ ).

To further confirm the negligible effect of PSD-95 on NBCn1-mediated $\mathrm{pH}_{\mathrm{i}}$ changes, we expressed NBCn1 and PSD-95 in Xenopus oocytes and measured $\mathrm{pH}_{\mathrm{i}}$ using a proton-selective microelectrode. In an oocyte expressing PSD-95 (Fig. 4A), the $\mathrm{pH}_{\mathrm{i}}$ was not recovered from $\mathrm{CO}_{2}$ induced acidification and instead reached steady-state. This confirms that PSD-95 alone does 
Fig. 3. Effect of PSD-95 on $\mathrm{pH}_{\mathrm{i}}$ changes $\mathbf{A}$ mediated by NBCn1 in HEK 293 cells. A) Representative $\mathrm{pH}_{\mathrm{i}}$ traces in HEK 293 cells expressing NBCn1 and either PSD-95 or none. Cells were superfused with $\mathrm{HCO}_{3}{ }^{-} / \mathrm{CO}_{2}$-free $\mathrm{HEPES}$ solution and then with a solution equilibrated with $33 \mathrm{mM} \quad \mathrm{HCO}_{3}^{-}, 5 \% \quad \mathrm{CO}_{2}$. Measurements were done at $37^{\circ} \mathrm{C}$.

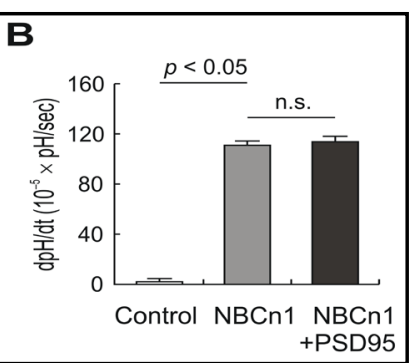

B

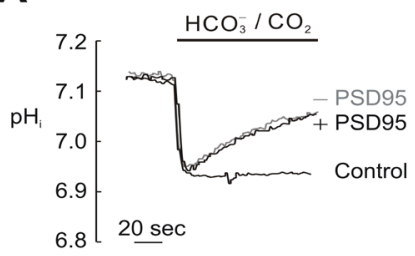

B) Mean rate of $\mathrm{pH}_{\mathrm{i}}$ recovery from $\mathrm{CO}_{2}$-induced acidification. The rate $\left(\mathrm{dpH}_{\mathrm{i}} / \mathrm{dt}\right.$; $\mathrm{pH}$ units per second) was calculated from a linear regression line during the first $30 \mathrm{sec}$ of recovery $(\mathrm{n}=8$ controls, $21 \mathrm{NBCn} 1$ cells, and 20 NBCn1/PSD-95 cells in three independent coverslips). ${ }^{* *}$ : significant compared to controls $(p<$ $0.05)$. n.s.: not significant $(p>0.05)$.

not induce $\mathrm{pH}_{\mathrm{i}}$ recovery. In an oocyte expressing NBCn1 (Fig. 4B), the $\mathrm{pH}_{\mathrm{i}}$ falls upon exposure to $\mathrm{HCO}_{3}{ }^{-} / \mathrm{CO}_{2}$, but was then recovered from the acidification as $\mathrm{NBCn} 1$ moved $\mathrm{HCO}_{3}{ }^{-}$into the oocyte and buffered intracellular $\mathrm{H}^{+}$. In an oocyte coexpressing the two proteins (Fig. 4C), the $\mathrm{pH}_{\mathrm{i}}$ was recovered at a similar rate compared to $\mathrm{NBCn} 1$ alone. Fig. $4 D$ summarizes the mean $\mathrm{pH}_{\mathrm{i}} / \mathrm{dt}$ calculated during the first 2 min of recovery $(\mathrm{n}=5$ for each). NBCn1 and NBCn1/PSD95 had similar $\mathrm{dpH}_{\mathrm{i}} / \mathrm{dt}$ values $\left(15.3 \pm 1.7 \times 10^{-5} \mathrm{pH}\right.$ units/sec for $\mathrm{NBCn} 1$ and $14.2 \pm 1.7 \times 10^{-5}$ $\mathrm{pH}$ units/sec for NBCn1/PSD-95; $p>0.05$ ). These values were significantly higher than that for PSD-95 alone $\left(3.0 \pm 2.2 \times 10^{-5} \mathrm{dpH}_{\mathrm{i}} / \mathrm{dt} ; p<0.05\right)$. Thus, consistent with the result from HEK 293 cells, PSD-95 has no effect on NBCn1 cotransport activity in Xenopus oocytes. Also, PSD-95 coimmunoprecipitated with NBCn1 in the lysates prepared from oocytes injected with NBCn1 and PSD-95, determined by coimmunoprecipitation (data not shown).

\section{PSD-95 increases channel-like activity of NBCn1}

We then tested whether PSD-95 affects channel-like activity of NBCn1 that produces a steady-state current in the $\mathrm{Na} / \mathrm{HCO}_{3}$-independent manner [2, 7]. For this analysis, $I-V$ relationships were determined by a stair-case voltage command from -120 to 60 $\mathrm{mV}$ in $\mathrm{HCO}_{3}^{-} / \mathrm{CO}_{2}$-free $\mathrm{ND} 96$ solution (the holding potential of $-60 \mathrm{mV}$ ). Uninjected controls and PSD-95-injected oocytes produced negligible basal currents (Fig. 5A). In contrast, oocytes expressing $\mathrm{NBCn} 1$ had distinct inward currents at negative potentials and distinct outward currents at positive potentials (Fig. 5B). These are hallmarks for NBCn1 channel-like activity. The membrane potential was shifted positively $(-54.1 \pm 0.7$ $\mathrm{mV}$ for controls and $-25.2 \pm 0.9 \mathrm{mV}$ for NBCn1), another hallmark. PSD-95 increased the currents. At $-54 \mathrm{mV}$, which is the average resting potential of control oocytes, the inward current of $130 \mathrm{nA}$ was generated by NBCn1, while $310 \mathrm{nA}$ was generated by NBCn1/PSD95. Fig. 5C summarizes the mean slope conductance measured near the zero-current voltage. The conductance was higher when the two proteins were coexpressed $(6.5$ $0.4 \mu \mathrm{S}$ for NBCn1 alone, $\mathrm{n}=4$ versus $11.4 \pm 2.2 \mu \mathrm{S}$ for NBCn1/PSD-95, $\mathrm{n}=5 ; p<0.05)$. PSD-95 coexpression caused the zero-current voltage to move positively $(-25.2 \pm 2.1 \mathrm{mV}$ versus -18.3 $\pm .4 .0 \mathrm{mV}, p<0.05$ ), the reason of which is unclear.

Blocking the PDZ interaction abolishes PSD-95-mediated increase in NBCn1 conductance

To ascertain that the increased NBCn1 conductance by PSD-95 was due to their interaction, we performed two sets of experiments. In the first experiment, we deleted the last four amino acids ETSL and tested whether the deletion abolishes the PSD-95-mediated increase in NBCn1 conductance. Fig. 6A shows the results. PSD-95 increased the mean conductance for $\mathrm{NBCn} 1(3.9 \pm 0.4 \mu \mathrm{S}$ for $\mathrm{NBCn} 1, \mathrm{n}=6$ versus $6.2 \pm 0.3 \mu \mathrm{S}$ for NBCn1/PSD$95, \mathrm{n}=7 ; p<0.05$ ), consistent with the above finding. However, PSD-95 failed to increase the conductance when ETSL was deleted $(4.0 \pm 0.3 \mu \mathrm{S}$ for NBCn1( $\Delta \mathrm{ETSL}) / \mathrm{NBCn} 1, \mathrm{n}=8)$. The deletion has negligible effect on NBCn1 function (data not shown), comparable with the previous report [26] that the C-terminal domain is not critical for function. In the second 


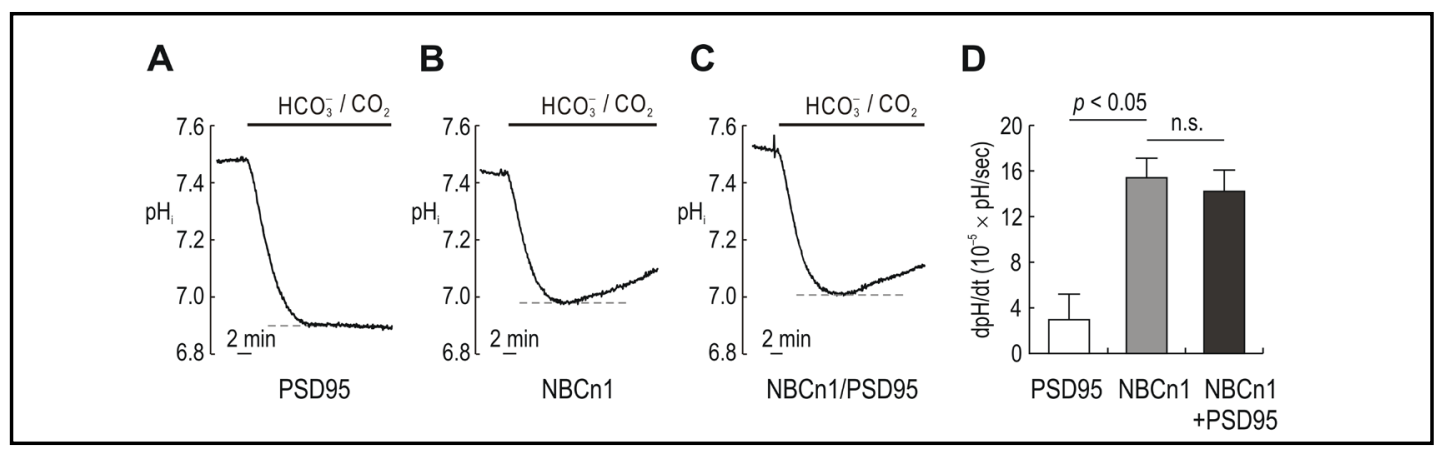

Fig. 4. Effect of PSD-95 on NBCn1-mediated $\mathrm{pH}_{\mathrm{i}}$ changes in Xenopus oocytes. A-C) Representative $\mathrm{pH}_{\mathrm{i}}$ traces in Xenopus oocytes expressing PSD-95, NBCn1, and NBCn1/PSD-95. Oocytes were superfused with $\mathrm{HCO}_{3}{ }^{-} / \mathrm{CO}_{2}$-free $\mathrm{ND} 96$ solution and then with a solution equilibrated with $25 \mathrm{mM} \mathrm{HCO}{ }_{3}^{-}, 5 \% \mathrm{CO}_{2}$. The $\mathrm{pH}_{\mathrm{i}}$ was measured with the proton-selective glass electrodes. D) Mean rate of $\mathrm{pH}_{\mathrm{i}}$ recovery from $\mathrm{CO}_{2}$-induced acidification. The $\mathrm{dpH}_{\mathrm{i}} / \mathrm{dt}$ was calculated from a linear regression line during the 2 min of recovery $(\mathrm{n}=5$ for each). *: significant compared to PSD-95 $(p<0.05)$.

experiment, we injected the peptide containing the last 15 amino acids of rat NBCn1 into oocytes expressing NBCn1 so that the peptide could compete and disrupt the interaction between the full-length NBCn 1 and PSD-95. The peptide $(0.05 \mu \mathrm{g} /$ oocyte $)$ was injected $48 \mathrm{~h}$ after NBCn1 and NBCn1/PSD-95 RNA injection, and then NBCn1-associated currents were measured $36 \mathrm{~h}$ later. Fig. $6 \mathrm{~B}$ shows the results. In oocytes expressing $\mathrm{NBCn} 1$, the mean slope conductance for NBCn 1 was unaffected by the peptide $(2.9 \pm 0.5 \mu \mathrm{S}$ for NBCn $1, \mathrm{n}=5$ versus $2.9 \pm 0.2 \mu \mathrm{S}$ for NBCn1 with the peptide, $\mathrm{n}=9 ; p>0.05$ ). However, in oocytes expressing NBCn1/PSD-95, the mean slope conductance was decreased by $57 \%$ by the peptide $(9.8 \pm$ $2.8 \mu \mathrm{S}$ for NBCn1/PSD-95, $\mathrm{n}=10$ versus $4.2 \pm 1.0 \mu \mathrm{S}$ for NBCn1/PSD-95 with the peptide, $\mathrm{n}=8 ; p<0.05$ ). Thus, the peptide competing with $\mathrm{NBCn} 1$ for the interaction with PSD-95 inhibited the NBCn1-mediated conductance.

\section{Discussion}

In this study, we found that PSD-95 interacts with $\mathrm{NBCn} 1$ and increases its channellike activity while negligibly effecting $\mathrm{Na} / \mathrm{HCO}_{3}$ cotransport activity. These findings not only provide additional information on the NBCn1/PSD-95 interaction we previously reported, but they also give a new foundation for understanding the molecular and functional role of NBCn1.

Acid/base regulation is important for maintaining ionic and $\mathrm{pH}$ homeostasis in neurons [27], and pH disturbance is linked to neurological dysfunctions such as ischemia, coma, and epilepsy $[28,29]$. Neurons possess regulatory mechanisms for maintaining $\mathrm{pH}_{\mathrm{i}}$ not to fall far below the normal ranges, and among these mechanisms is $\mathrm{Na} / \mathrm{HCO}_{3}$ cotransport mediated by NBCn1. NBCn1 gene disruption results in severe defects in hearing and vision [5], as well as abnormal regulation of vascular tone [6], and NBCn1 knockdown reduces glutamate toxicity in neurons [30]. These reports provide strong evidence that NBCn1-mediated $\mathrm{pH}$ regulation play critical roles in tissues where the transporter is present [14]. Determined by electron microscopic immunoperoxidase, we demonstrate a predominant localization of NBCn1 in postsynaptic membranes (Fig. 1). Double label immunofluorescence of hippocampal neurons shows a partial colocalization of NBCn1 and PSD-95 in relatively large dendrites, consistent with the previous report [13]. The finding of $\mathrm{NBCn} 1$ in postsynaptic membranes brings up an interesting point on $\mathrm{Na} / \mathrm{HCO}_{3}$ transporters at synapses. Recent studies show that $\mathrm{NBCn} 2$ is present in postsynaptic membranes, whereas the $\mathrm{Na}^{+}$-driven $\mathrm{Cl} / \mathrm{HCO}_{3}$ exchanger NDCBE is located in synaptic vesicles [31]. Thus, $\mathrm{NBCn} 1$ and $\mathrm{NBCn} 2$ govern postsynaptic neuronal $\mathrm{pH}_{\mathrm{i}}$ and/or synaptic cleft $\mathrm{pH}$, while the $\mathrm{Cl}^{-}$-dependent $\mathrm{Na} / \mathrm{HCO}_{3}$ transporter NDCBE governs synaptic vesicular $\mathrm{pH}$ in the presynaptic terminal [24]. Whether $\mathrm{NBCn} 2$ is a $\mathrm{Cl}^{-}$-independent $\mathrm{Na} / \mathrm{HCO}_{3}$ transporter is controversial. We and our colleagues reported that $\mathrm{NBCn} 2$ moves 
Fig. 5. Effect of PSD-95 on NBCn1 conductance in Xenopus oocytes. A) Current-voltage $(I-V)$ relationships in oocytes injected with water or expressing PSD95. Oocytes were clamped at $-60 \mathrm{mV}$ in $\mathrm{HCO}_{3}^{-} / \mathrm{CO}_{2}$-free ND96 solution and subjected to a voltage command stepping from -120 to $+60 \mathrm{mV}$ with
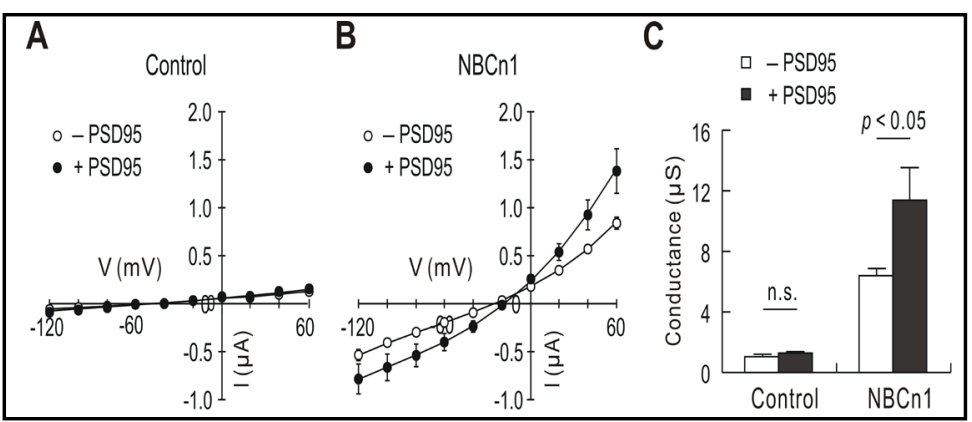

$20 \mathrm{mV}$ increments. Steady-state currents were recorded ( $\mathrm{n}=5$ for each). B) $I-V$ relationships in oocytes expressing NBCn1 or NBCn1/PSD-95. Large inward currents at negative potentials and large outward currents at positive potentials are hallmarks for $\mathrm{NBCn} 1$ conductance. Recordings were done with 4 oocytes injected with NBCn1 and 5 oocytes injected with NBCn1/PSD-95. C) Mean slope conductance. The slope was determined near the zero-current voltage in $I-V$ plots.

Fig. 6. Effect of the PDZ interaction on $\mathrm{NBCn} 1$ conductance. A) Mean slope conductance in oocytes expressing NBCn1, NBCn1/PSD-95, NBCn1( $\Delta \mathrm{ETSL}) /$ PSD-95, and controls. Values were obtained from I-V relationships determined using the protocol in Fig. 5 ( $\mathrm{n}=5$ controls, 6 NBCn1, 7 NBCn1/PSD-95, and 8 NBCn1( $\triangle$ ETSL)/PSD-95). B) Effect of the C-terminal peptide on NBCn1 conductance. Oocytes were injected with NBCn1 or NBCn1/PSD-95 and $48 \mathrm{~h}$ later were injected with the peptide corresponding to the last 15 amino acids of the transporter $(0.05 \mu \mathrm{g}$ per oocyte). NBCn1 conductance was then measured $36 \mathrm{~h}$ later. Data

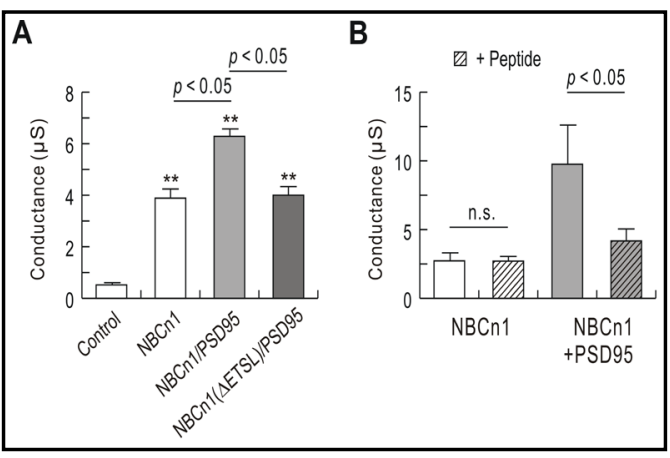
were obtained from 5 NBCn1, 9 NBCn1 with the peptide, 10 NBCn1/PSD-95, and 8 NBCn1/PSD-95 with the peptide.

$\mathrm{Na}^{+}$and $\mathrm{HCO}_{3}{ }^{-}$, but not $\mathrm{Cl}^{-}$[32]. The $\mathrm{Cl}^{-}$influx caused by $\mathrm{NBCn} 2$ is due to $\mathrm{Cl}^{-}$self-exchange uncoupled to $\mathrm{Na} / \mathrm{HCO}_{3}$ transport. On the other hand, Damkier et al [33] reported that $\mathrm{NBCn} 2$ moves $\mathrm{Na}^{+}$and $\mathrm{HCO}_{3}^{-}$in exchange for $\mathrm{Cl}^{-}$. In this case, $\mathrm{NBCn} 2$ is similar to NDCBE in function. Regardless, it is evident that $\mathrm{NBCn} 2$ has the ability to move $\mathrm{Cl}^{-}$either directly or indirectly and is distinct from NBCn1.

The pull-down assay shows PSD-95 interaction with NBCn1, but not NBCn2 (Fig. 2A). One possible explanation is that $\mathrm{NBCn} 2$ variants containing the PDZ-binding motif are absent at synapse. NBCn2 immunofluorescence signals in neurons appear to be markedly diffused through the cytosol in cell bodies and dendrites [34]. Another possible explanation is that GST/NBCn2 requires a more stringent binding condition than GST/NBCn1 to pull down PSD95 from brain lysates. Different PDZ motifs have different binding affinities of a given PDZ domain, and an optimal binding depends upon in vitro conditions such as ion stringency and temperature [24]. The difference between $\mathrm{NBCn} 1$ and $\mathrm{NBCn} 2$ is the second last amino acid in the PDZ motif (ETSL vs. ETCL). The second last residue is known to be least critical for PDZ-mediated interaction, but some PDZ domains including PSD-95 can distinguish amino acids at this position [24].

The interaction between NBCn 1 and PSD-95 is confirmed by coimmunoprecipitation in HEK 293 cells (Fig. 2B). This interaction occurs without influencing PSD-95's essential ability to interact with NMDA receptors via the first and second PDZ domains [14]. The binding domain for NBCn1 is less clear although our preliminary proteomic analysis shows the third PDZ domain of PSD-95 being responsible for NBCn1 interaction (unpublished observation). Thus, NBCn1 and NR2A do not share the binding domains in PSD-95. In this sense, there is a possibility that NBCn 1 clusters with NMDA receptors via PSD-95 to form a ternary complex containing NBCn1/PSD-95/NR2A although it is unclear if this complex exists in neurons. 
Nonetheless, we do not exclude another possibility that our coimmunoprecipitation data could be due to partial expression of the three proteins in transfected cells. NBCn1/PSD95 interaction would not affect NR2A/PSD-95 interaction if some cells express PSD-95 and NBCn1 while others express PSD-95 and NR2A. Regarding the binding strength, we observe that a large fraction of NR2A proteins in the lysates bind to PSD-95, while a small fraction of NBCn1 proteins bind to PSD-95. It could be due to either different binding affinities between the two interactions or different numbers of PSD-95 PDZ domains for NBCn1 or NR2A. A stronger intensity does not necessarily reflect a biologically more significant role of the corresponding interaction, although we believe that PSD-95/NR2A interaction would be more functionally significant than NBCn1/PSD-95 interaction.

Our $\mathrm{pH}$ experiments reveal no significant difference in $\mathrm{dpH}_{\mathrm{i}} / \mathrm{dt}$ between $\mathrm{NBCn} 1$ and NBCn1/PSD-95 in both HEK 293 cells and Xenopus oocytes. Thus, PSD-95 has negligible effect on NBCn1 cotransport regardless of two different expression systems. On the other hand, PSD-95 increases the transporter's channel-like activity that produces a steady-state inward current at the resting voltage (Fig. 5). PSD-95 increases the slope conductance without significantly altering the zero-current voltage, implying that more pores are opened by PSD95. Deleting the C-terminal ETSL abolishes the stimulatory effect of PSD-95, and the peptide containing ETSL competes with the full-length transporter (Fig. 6). Together, these results strongly support the idea that PSD-95 binds to the transporter and stimulates its channellike activity. We propose that the channel-like activity may occur via an intermolecular cavity of multimeric NBCn1 proteins. NBCe1 (SLC4A4), which has high amino acid sequence homology with NBCn1, forms a dimer consisting of two individually functional subunits [35, 36]. The distantly related bicarbonate transporters AE1 (SLC4A1) and AE2 (SLC4A2) are also homodimers [37]. We believe that NBCn1 is also in a dimeric form with each functional subunit, and PSD-95 may facilitate the dimerization process. We also note that PSD-95 is a dimer [38]. A similar example of PDZ protein-mediated intermolecular modification is found in CFTR [43]. The PDZ protein CAP70 (PDZK1) enhances intermolecular CFTR-CFTR contact and switches CFTR channels to a more active conducting state.

Regardless of the underlying mechanism, PSD-95 substantially enhances NBCn1mediated steady state currents (Fig. 5) that raise intracellular $\mathrm{Na}^{+}$levels in mammalian cells and frog oocytes $[2,7]$. The increased $\mathrm{Na}^{+}$levels would lower an electrochemical $\mathrm{Na}^{+}$gradient across cell membranes and reduce a driving force of sodium channels/transporters if they are present with NBCn1 in the same cells. This inhibitory effect would be augmented by PSD95. It is important to note that the channel-like activity of NBCn1 has been characterized so far in heterologous overexpression systems, which are different from the native system. It is unclear whether NBCn1 has a similar activity and is stimulated by PSD-95 in neurons, where the interaction of NBCn1 and PSD-95 depends upon the spatial distribution and expression level of the two proteins. PSD-95 binds to a large number of different postsynaptic proteins and forms a constituent of macromolecular complexes. Also, NBCn1 is expected to bind to different PDZ proteins via its C-terminal PDZ motif. It is likely that the interaction is very limited and local in neurons.

$\mathrm{NBCn} 1$ is not the only $\mathrm{HCO}_{3}^{-}$transporters exhibiting channel-like activity, and other transporters have similar properties. AE1 in erythrocytes mediates a conductive anion flux that is DIDS-insensitive and increases with increasing membrane hyperpolarization [39]. The $\mathrm{Cl} / \mathrm{HCO}_{3}$ exchangers Slc26a3 (DRA, CLD) and Slc26a6 (CFEX, PAT-1) mediate large $\mathrm{NO}_{3}^{-}$and $\mathrm{SCN}^{-}$currents uncoupled to $\mathrm{OH}^{-}$or $\mathrm{HCO}_{3}^{-}$transport $[40,41]$. The electroneutral NDAE1 in Drosophila has a small inward current [42]. The functional implication of these conductance properties is unclear.

In summary, our study shows that PSD-95 binds to $\mathrm{NBCn} 1$ via the C-terminal PDZ-motif and alters NBCn1-mediated conductance, but not $\mathrm{Na} / \mathrm{HCO}_{3}$ cotransport. To our knowledge, these findings indicate for the first time that PSD-95 separates NBCn1's dual activities. It will be interesting to investigate whether a similar mechanism is found in neurons in future experiments. 


\section{Acknowledgements}

We thank Jeff Pare and Susan Jenkins for technical assistance with electron microscopy procedures, Drs. Suzanne Zukin (Albert Einstein College) and Makato Inui (Yamaguchi University) for providing PSD-95, and Drs. Randy Hall and Steve Traynelis (Pharmacology, Emory) for providing PSD-95, NR1A, and NR2A plasmids. This work was supported by grants from the NIH GM078502, American Heart Association, and Emory URC (I. C.), Yerkes National Primate Center NIH base grant RR00165 (Y. S.), and DK061418 (C.C.Y.).

\section{References}

1 Pushkin A, Abuladze N, Lee I, Newman D, Hwang J, Kurtz I: Cloning, tissue distribution, genomic organization, and functional characterization of NBC3, a new member of the sodium bicarbonate cotransporter family. J Biol Chem 1999;274:16569-16575.

2 Choi I, Aalkjaer C, Boulpaep EL, Boron WF: An electroneutral sodium/bicarbonate cotransporter NBCn1 and associated sodium channel. Nature 2000;405:571-575.

- 3 Cordat E, Casey JR: Bicarbonate transport in cell physiology and disease. Biochem J 2009;417:423-439.

4 Lauritzen G, Jensen MB, Boedtkjer E, Dybboe R, Aalkjaer C, Nylandsted J, Pedersen SF: NBCn1 and NHE1 expression and activity in DeltaNErbB2 receptor-expressing MCF-7 breast cancer cells: contributions to pHi regulation and chemotherapy resistance. Exp Cell Res 2010;316:2538-2553.

-5 Bok D, Galbraith G, Lopez I, Woodruff M, Nusinowitz S, BeltrandelRio H, Huang W, Zhao S, Geske R, Montgomery C, Van S, I, Friddle C, Platt K, Sparks MJ, Pushkin A, Abuladze N, Ishiyama A, Dukkipati R, Liu W, Kurtz I: Blindness and auditory impairment caused by loss of the sodium bicarbonate cotransporter NBC3. Nat Genet 2003;34:313-319.

6 Boedtkjer E, Praetorius J, Matchkov VV, Stankevicius E, Mogensen S, Fuchtbauer AC, Simonsen U, Fuchtbauer EM, Aalkjaer C: Disruption of $\mathrm{Na}^{+}, \mathrm{HCO}^{-}$cotransporter NBCn1 (slc4a7) inhibits NO-mediated vasorelaxation, smooth muscle $\mathrm{Ca}^{2+}$ sensitivity, and hypertension development in mice. Circulation 2011;124:1819-1829.

7 Cooper DS, Saxena NC, Yang HS, Lee HJ, Moring AG, Lee A, Choi I: Molecular and functional characterization of the electroneutral $\mathrm{Na} / \mathrm{HCO}_{3}$ cotransporter $\mathrm{NBCn} 1$ in rat hippocampal neurons. J Biol Chem 2005;280:17823-17830.

8 Boron WF, Chen L, Parker MD: Modular structure of sodium-coupled bicarbonate transporters. J Exp Biol 2009;212:1697-1706.

$>9$ Pushkin A, Abuladze N, Newman D, Muronets V, Sassani P, Tatishchev S, Kurtz I: The COOH termini of NBC3 and the 56-kDa $\mathrm{H}^{+}$-ATPase subunit are PDZ motifs involved in their interaction. Am J Physiol Cell Physiol 2003;284:C667-C673.

10 Park M, Ko SBH, Davidson N, Muallem G, Thomas PJ, Pushkin A, Lee K, Kim JY, Lee MG, Muallem S: The cystic fibrosis transmembrane conductance regulator interacts with and regulates the activity of the HCO3 salvage transporter human $\mathrm{Na}^{+}$-HCO3 cotransporter isoform 3. J Biol Chem 2002;277:50503-50509.

11 Reiners J, van Wijk E, Marker T, Zimmermann U, Jurgens K, te Brinke H, Overlack N, Roepman R, Knipper M, Kremer H, Wolfrum U: Scaffold protein harmonin (USH1C) provides molecular links between Usher syndrome type 1 and type 2. Hum Mol Genet 2005;14:3933-3943.

12 Loiselle FB, Morgan PE, Alvarez BV, Casey JR: Regulation of the human $\mathrm{NBC} \mathrm{Na}^{+} / \mathrm{HCO}_{3}-$ cotransporter by carbonic anhydrase II and PKA. Am J Physiol Cell Physiol 2004;286:C1423-C1433.

13 Park HJ, Rajbhandari I, Yang HS, Lee S, Cucoranu D, Cooper DS, Klein JD, Sands JM, Choi I: Neuronal expression of sodium/bicarbonate cotransporter NBCn1 (SLC4A7) and its response to chronic metabolic acidosis. Am J Physiol Cell Physiol 2010;298:C1018-C1028.

14 Kim E, Sheng M: PDZ domain proteins of synapses. Nat Rev Neurosci 2004;5:771-781.

15 Sheng M, Hoogenraad CC: The postsynaptic architecture of excitatory synapses: a more quantitative view. Annu Rev Biochem 2007;76:823-847.

16 Raju DV, Shah DJ, Wright TM, Hall RA, Smith Y: Differential synaptology of vGluT2-containing thalamostriatal afferents between the patch and matrix compartments in rats. J Comp Neurol 2006;499:231-243.

17 Praetorius J, Kim YH, Bouzinova EV, Frische S, Rojek A, Aalkjaer C, Nielsen S: NBCn1 is a basolateral $\mathrm{Na}^{+}-\mathrm{HCO}_{3}{ }^{-}$cotransporter in rat kidney inner medullary collecting ducts. Am J Physiol Renal Physiol 2004;286:F903-F912. 
18 Park HJ, Rajbhandari I, Yang HS, Lee S, Cucoranu D, Cooper DS, Klein JD, Sands JM, Choi I: Neuronal Expression of Sodium/Bicarbonate Cotransporter NBCn1 (SLC4A7) and its Response to Chronic Metabolic Acidosis. Am J Physiol Cell Physiol 2010; 298:C1018-C1028.

19 Thomas JA, Buchsbaum RN, Zimniak A, Racker E: Intracellular pH measurements in Ehrlich ascites tumor cells utilizing spectroscopic probes generated in situ. Biochemistry 1979;18:2210-2218.

20 Chen LM, Liu Y, Boron WF: Role of an extracellular loop in determining the stoichiometry of $\mathrm{Na}^{+}-\mathrm{HCO}_{3}-$ cotransporters. J Physiol 2011;589:877-890.

21 Yang HS, Cooper DS, Rajbhandari I, Park HJ, Lee S, Choi I: Inhibition of rat $\mathrm{Na}^{+}(-) \mathrm{HCO}_{3}{ }^{-}$cotransporter (NBCn1) function and expression by the alternative splice domain. Exp Physiol 2009;94:1114-1123.

22 Damkier HH, Nielsen S, Praetorius J: Molecular expression of SLC4-derived $\mathrm{Na}^{+}$-dependent anion transporters in selected human tissues. Am J Physiol Regul Integr Comp Physiol 2007;293:R2136-R2146.

23 Hunt CA, Schenker LJ, Kennedy MB: PSD-95 is associated with the postsynaptic density and not with the presynaptic membrane at forebrain synapses. J Neurosci 1996;16:1380-1388.

24 Sheng M, Sala C: PDZ domains and the organization of supramolecular complexes. Annu Rev Neurosci 2001;24:1-29.

25 Kornau HC, Schenker LT, Kennedy MB, Seeburg PH: Domain interaction between NMDA receptor subunits and the postsynaptic density protein PSD-95. Science 1995;269:1737-1740.

26 Choi I, Yang HS, Boron WF: The electrogenicity of the sodium/bicarbonate cotransporter NBCe1 requires interactions among transmembrane segments of the transporter. J Physiol (Lond) 2007;578:131-142.

27 Chesler M: Regulation and modulation of pH in the brain. Physiol Rev 2003;83:1183-1221.

28 Majumdar D, Bevensee MO: Na-coupled bicarbonate transporters of the solute carrier 4 family in the nervous system: function, localization, and relevance to neurologic function. Neuroscience 2010;171:951972.

29 Siesjo BK: Acidosis and ischemic brain damage. Neurochem Pathol 1988;9:31-88.

-30 Cooper DS, Yang HS, He P, Kim E, Rajbhandari I, Yun CC, Choi I: Sodium/bicarbonate cotransporter NBCn1/ slc4a7 increases cytotoxicity in magnesium depletion in primary cultures of hippocampal neurons. Eur J Neurosci 2009;29:437-446.

-31 Sinning A, Liebmann L, Kougioumtzes A, Westermann M, Bruehl C, Hubner CA: Synaptic glutamate release is modulated by the $\mathrm{Na}^{+}$-driven Cl-/HCO exchanger Slc4a8. J Neurosci 2011;31:7300-7311.

-32 Parker MD, Musa-Aziz R, Rojas jd, Choi I, Daly CM, Boron WF: Characterization of human SLC4A10 as an electroneutral $\mathrm{Na} / \mathrm{HCO} 3$ cotransporter (NBCn2) with Cl- self-exchange activity. J Biol Chem 2008;283:12777-12788.

33 Damkier HH, Aalkjaer C, Praetorius J: $\mathrm{Na}^{+}$-dependent HCO3-import by the slc4a10 gene product involves Cl- export. J Biol Chem 2010;285:26998-27007.

34 Liu Y, Xu K, Chen LM, Sun X, Parker MD, Kelly ML, LaManna JC, Boron WF: Distribution of NBCn2 (SLC4A10) splice variants in mouse brain. Neuroscience 2010;169:951-964.

35 Kao L, Sassani P, Azimov R, Pushkin A, Abuladze N, Peti-Peterdi J, Liu W, Newman D, Kurtz I: Oligomeric structure and minimal functional unit of the electrogenic sodium bicarbonate cotransporter NBCe1-A. J Biol Chem 2008;283:26782-26794.

-36 Gill HS, Boron WF: Expression and purification of the cytoplasmic N-terminal domain of the Na/HCO3 cotransporter NBCe1-A: structural insights from a generalized approach. Protein Expr Purif 2006;49:228234.

37 Alper SL: Molecular physiology of SLC4 anion exchangers. Exp Physiol 2006;91:153-161.

-38 Hsueh YP, Kim E, Sheng M: Disulfide-linked head-to-head multimerization in the mechanism of ion channel clustering by PSD-95. Neuron 1997;18:803-814.

39 Freedman JC, Novak TS: Electrodiffusion, barrier, and gating analysis of DIDS-insensitive chloride conductance in human red blood cells treated with valinomycin or gramicidin. J Gen Physiol 1997;109:201216.

40 Ko SB, Shcheynikov N, Choi JY, Luo X, Ishibashi K, Thomas PJ, Kim JY, Kim KH, Lee MG, Naruse S, Muallem $\mathrm{S}$ : A molecular mechanism for aberrant CFTR-dependent $\mathrm{HCO}_{3}{ }^{-}$transport in cystic fibrosis. EMBO J 2002;21:5662-5672.

-41 Shcheynikov N, Yang D, Wang Y, Zeng W, Karniski LP, So I, Wall SM, Muallem S: The Slc26a4 transporter functions as an electroneutral $\mathrm{Cl}^{-} / \mathrm{I}^{-} / \mathrm{HCO}_{3}{ }^{-}$exchanger: role of Slc26a4 and Slc26a6 in I- and in regulation of CFTR in the parotid duct. J Physiol 2008;586:3813-3824.

42 Romero MF, Henry D, Nelson S, Harte PJ, Dillon AK, Sciortino CM: Cloning and characterization of a $\mathrm{Na}^{+}-$ driven anion exchanger (NDAE1). A new bicarbonate transporter. J Biol Chem 2000;275:24552-24559.

43 Wang S, Yue H, Derin RB, Guggino WB, Li M: Accessory protein facilitated CFTR-CFTR interaction, a

molecular mechanism to potentiate the chloride channel activity. Cell 2000; 103:169-179. 